\title{
ABSTRACTS
}

\section{THE EAR.}

Concerning the Definition, Nomenclature, and Classification of Diseases of the Middle Ear. A. ScHeibe, Erlangen. (Archiv. für Ohren-, Nasen-, und Kehlkopfheilkunde, Band cxiii., Heft I, April I925.)

Scheibe observes that prior to the introduction of the ear-speculum, diseases of the middle ear were classified as acute middle-ear catarrh, chronic niddle-ear catarrh, acute middle-ear suppuration, and chronic middle-ear suppuration.

In 1856 , von Tröltsch added a type in which "the patient hears nothing and the doctor sees nothing"; and so gradually our modern conception of diseases of the middle ear evolved. Though the term

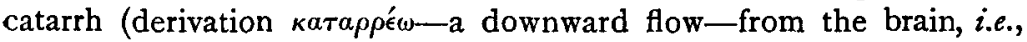
purulent rhinitis) now signifies inflammation of any mucous membrane, it does not accurately describe tubal obstruction with transudation, still less disease of the labyrinth capsule. The word catarrh, Scheibe considers, should be expunged from any future classification of diseases of the middle ear. He gives his reasons in favour of the following classification into inflammatory and tubal obstruction with transudation.

Inflammatory:-I. Acute otitis media (with and without perforation): (a) simple, and $(b)$ necrosing.

2. Chronic purulent otitis media: (a) simple, and $(b)$ with cholesteatoma.

3. Residues with persistent or cicatrised perforation: (a) after acute, necrosing middle-ear suppuration; $(b)$ after chronic simple middle-ear suppuration; $(c)$ after cholesteatomatous suppuration.

4. Acute residue or re-infection: (a) residues of acute, necrosing middle-ear suppuration; $(b)$ residues of chronic simple suppuration; (c) residues of cholesteatomatous suppuration.

WM. OLIVER LODGE.

\section{The Bacteriology of Ear Infections. A. M. Dunlap. (China Medical Journal, xxxix., No. 4, p. 33r.)}

The writer pleads for a routine bacteriological examination of all ear discharges, and relates the experience at the Peking Union Medical College with regard to the assistance it affords in the diagnosis and treatment of infected ears. It was found that Streptococcus hamolyticus was by far the most common organism found. The discharge in these cases is characteristic-profuse, straw-coloured, and blood-tinged. The quantity during twenty-four hours is considerably more than in any other ear infection, with the possible exception of pneumococcus. 


\section{Abstracts}

Leucocytosis ranges from 12,000 to $2 \mathrm{r}, 000$. It is the type which follows scarlet fever, and is of all infections the most serious. Nonhæmolytic streptococcic infections clear up much more rapidly.

In Peking Dunlap has seen no primary infections from KlebsLöffler Bacillus; all his cases were secondary. In pneumococcus (Type II) the discharge reminds one of $S$. hamolyticus, but is not so long sustained.

Aspergillus niger is often encountered in the Orient, and may cause a mild, low-grade infection with moderate amount of discharge.

Dr Dunlap considers that a knowledge of the type and virulency of the invading organism is invaluable in diagnosis and treatment.

Macleod Yearsley.

Contribution to the Study of the Pathogenesis and Therapeutics of Otospongiosis (Otosclerosis): The Basal Metabolism in Otospongiosis. R. Jousseaume, Paris. (Annales des Maladies de l'Oreille, du Larynx, du Nez et du Pharynx, January 1925.)

In a historical survey of the study of this disease, the author admits that lately the possibility of mal-function of the endocrine glands has already been considered as the cause of otosclerosis. He has studied carefully five patients suffering from this disease, both aurally and as to their basal metabolism, and has placed his findings and conclusions under the following headings - A. Etiological arguments for the endocrine origin of otosclerosis: (a) Nearly all the cases of true otosclerosis occur in women, and the ductless glands cause far greater metabolic fluctuation in women than in men. The incidence of puberty, the menses, pregnancy, lactation, and the menopause cause great reaction on the body tissues and are the results of endocrine action. (b) The development of otosclerosis varies with the activity of the ovaries (though the author states that another gland has an even closer association with otosclerosis, the pituitary). Otosclerosis commences about puberty, becomes worse during pregnancy and lactation, and is arrested after the menopause. Escat has reported a case in which total hysterectomy was performed in an otosclerotic for disease of the adnexa, with great benefit to the ear condition. (c) The disease is both symmetrical and symptomatic, both labyrinthine capsules being affected, resembling in some respects rickets, osteomalacia, and acromegaly. (d) The author states that the cases called by him otosclerosis have had no middle-ear catarrh, no affection of the nose or throat, no evidence of the rheumatic or diabetic diathesis, and no taint of syphilis. (e) The disease is most frequently hereditary.

B. Study of the basal metabolism: Sezary states that the ambushes which menace the adventurer into the realm of endocrinology are 


\section{The Ear}

numerous. Under this heading, in these five cases, has been included careful morphological and radiographic examination, abnormalities of the nervous and genital systems, investigation of the blood, the circulation, and the various metabolic changes. The basal metabolism is calculated in the amount of energy set free from a square metre of body surface, in calories, in an hour, the patient being in a room at a set temperature protected from cold.

The results of this investigation were as follows:-

I. In all five patients the basal metabolism was definitely low.

2. Four of the five were young girls of 14 to 16 , the fifth was a woman of 33 , and in each case the condition started at puberty.

3. In one case the menstrual flow was normal in quantity, in the others the flow was much increased.

C. Anatomical pathology: This is described fairly fully in three stages; hypervascularity of the labyrinth, accentuation of the process of bone-absorption, i.e., otospongiosis, and a third period in which new bone is laid down in mass, i.e., otosclerosis.

D. Therapeutics: This is discussed under general and local. On general lines, the author thinks that the exhibition of phosphorus, calcium, and fluorine is indicated, as tending to prevent the boneabsorption, and he thinks that this period is due to mal-function of the pituitary, and he advises that pituitary extract be administered. With regard to local treatment, this may be summed up as follows: "The worst day in the life of an otosclerotic is the day in which he meets an energetic aurist."

Gavin Young.

\section{The Alleviation of Chronic Progressive Deafness. G. C. Cathcart. (Lancet, r925, Vol. ii., p. 968.)}

The author gives a record of roo cases treated by the ZündBurguet electrophonoide method, the use of which does not appear to have been attended with any remarkable results in this country until now. Cathcart, however, considers that, when properly carried out, the Zünd-Burguet apparatus affords the most substantial advance of recent years in the treatment of chronic progressive deafness. Of his cases, he gives 68 per cent. as definitely improved, comprising 8 I per cent. of nerve deafness, 67 per cent. of chronic otitis media, and 55 per cent. of otosclerosis. These figures, he remarks, cannot be lightly dismissed as a mere manifestation of suggestion or autosuggestion. As regards tinnitus, his records show that this treatment not only alleviates it but often causes it to disappear completely. "It is not an exaggeration, therefore, to claim that the electrophonoide treatment, when properly carried out, can and often does cure tinnitus." MACLEOD YEARSLEY. 


\title{
Abstracts
}

\author{
NASO-PHARYNX AND PHARYNX.
}

\section{Persistence of the Cranio-Pharyngeal Canal and the Adenoid Operation. \\ OTto LEISzE. (Archiv. für-Nasen-, Ohren-, und Kehlkopfheilkunde, Band cxiii., Heft r.)}

In 1922 , Pilpel reported the case of a child in whom an adenoid operation produced a fatal meningitis owing to persistence of the communication between the naso-pharynx (Rathke's pouch) and the sella turcica.

A youth of 18 , in whom a variety of minor cranial malformations was present, recently came under Leisze's observation. Two photographs show projecting ears with adherent lobules and epicanthus. These were familial peculiarities. A skiagram shows a retained canine tooth. A mass of lymphoid tissue in the naso-pharynx presented a median cleft through which a fine probe could be introduced to a depth of a few millimetres. Histologically this was found to consist of adenoid tissue only, no trace of pituitary substance being found.

In spite of the rarity of the condition, the possibility of persistent cranio-pharyngeal canal should always be borne in mind when other cranial malformations are found to exist.

$$
\text { WM. Oliver Lodge. }
$$

Diverticulum of the Pharynx. J. W. Thomson. (Lancet, 1925, Vol. ii., p. 1078.)

The writer describes a case of diverticulum in a woman, aged 63 . Difficulty of swallowing existed for fourteen to fifteen years. Operation was at first refused, but agreed to five months later. Preliminary gastrostomy was carried out. Diverticulum was removed in one operation five weeks later. Recovery was uneventful, and the patient was in good health and gaining weight. Macleod Yearsley.

A New Tampon for Tonsil and Adenoid Operations. Louis M. Pearlman, M.D., New York. (American Journal of Surgery, April 1925.)

In this short paper the author draws attention to the advantages of a tampon of lamb's wool instead of the common tampon of gauze.

The lamb's wool is covered over with one layer of gauze and sterilised in the usual manner. The texture is soft and velvety and does not cause trauma. It is four times as compressible as gauze, and a tampon, large enough to fill the naso-pharynx or the tonsillar fossa, can be compressed in a sponge-holder to a size small enough to slip easily into position without injury to the pillars. Resilient and flexible, the lamb's wool tampon on being released from the holder 


\section{Peroral Endoscopy}

completely fills the naso-pharynx or tonsillar fossa, remaining in contact with denuded tissues and producing effective hæmostasis. It is a non-absorbent tampon, and acts as a hæmostat immediately upon being placed in contact with the tissues. It can be allowed to remain in position for a comparatively long time without adhering to the tissues.

The author has satisfied himself of the advantages of the lamb's wool tampon over the gauze tampon in a series of more than a thousand cases.

Nicol M. Rankin.

\section{PERORAL ENDOSCOPY.}

The Surgical Treatment of Cardiospasm. A. J. WaLton, F.R.C.S. (Brit. Journ. of Surgery, I925, Vol. xiii., pp. 701-737.)

In the introduction to his paper the author discusses the general considerations of this most important, and still unsolved disease, known under the several names of cardiospasm, œsophagectasia, achalasia of the cardia, idiopathic dilatation of the csophagus, hiatal cesophagismus, and phreno-spasm.

He defines the condition as one of dilatation and hypertrophy of the cesophagus, in which, on post-mortem examination, no obstruction can be found distal to the dilatation. He refers to the pathological changes seen in the advanced stage (which are those generally found after death) as well shown in the series of 14 post-mortem specimens collected and described by Irwin Moore, of which he reproduces three illustrations, two exhibiting the common flask-shaped and fusiform varieties, and the third, the S-shaped type, the dilatation extending to the cardia.

The term "cardiospasm" originated from the earlier description of these dilatations, which were believed to extend to the cardiac orifice, a spastic contraction of the circular muscular fibres (sphincter) surrounding this orifice giving rise to the condition, but no irrefragable evidence of such a spasm, at this orifice, has ever been produced.

Chevalier Jackson was the first to suggest that the obstruction was not at the cardiac orifice, but at the level of the diaphragm, a view strongly supported by Hill. In the majority of X-ray studies of this disease which have been recorded, the dilatation extended only to the level of the diaphragm, and this was shown in most of the author's cases. It was also the case, as the author points out, in I I out of 14 specimens in Irwin Moore's series, the dilatation ceasing at the level of the diaphragm, a portion of the undilated tube-the phreno-cardiac canal-being below the diaphragm; in only three cases did it reach the cardiac orifice.

The frequency of cases of alleged true cardiospasm- $\mathbf{r} 6$ cases in 553 


\section{Abstracts}

the author's clinical experience, covering a period of eleven yearsis 17.8 per cent., unusually high, as he remarks. Amongst the other varieties of œsophageal obstruction observed by him were 65 cases of carcinoma, $x$ of fibrous stenosis, and 3 of pharyngeal pouch.

The frequency in general post-mortems is shown by the occurrence of 7 cases in $833^{2}$ autopsies at the London Hospital between 1908 and r9i5. The average age at which treatment was sought was $52 \frac{1}{2}$ years.

The symptoms are variable, in most cases gradual in onset, in some abrupt, in the majority dating back several years, and in some to childhood, and always progressing; they consist in a feeling of fullness and discomfort, with severe intermittent epigastric pain after food in advanced stages, radiating to the back, in regurgitation or vomiting of food, and emaciation.

The author has come to the conclusion that the condition is congenital, although the symptoms may not become evident until later in life.

The various theories in connection with the etiology of the disease are discussed in detail, the author's opinion being in favour of spasm rather than of inco-ordination, though why this alleged spasm should be found more commonly at the level of the diaphragm than at the cardiac orifice has not at present been convincingly explained. Walton thinks it possible that the food is held up by a spasm of the phrenocardiac portion of the osophagus, and considers that there is not sufficient evidence to exclude entirely the presence of spasm of the extreme lower end of the œesophagus, i.e., at the cardiac orifice, and that further search must be made for the cause of the spasm.

The lower end of the csophagus, as seen through the œsophagoscope, is described as tightly constricted, and this was confirmed by $\mathrm{X}$-rays in all his cases, which is contrary to the finding of Brown Kelly that the opening may be seen to relax and contract. Again, a small bougie, introduced endoscopically, passed through the orifice only with difficulty, and was firmly gripped in contra-distinction to the findings of some observers who note that a tube can be easily passed without being gripped, as it would be if the muscle was in spasm. Other observers have confirmed this difficulty in some cases. The author thinks this may possibly be explained by the existence of two distinct groups of cases, the early or slight, in which bougies can be passed readily, and the later or severe, in which no bougie, unless very small, will pass beyond the constriction.

While agreeing that the well-known hydrostatic apparatus of Plummer is the best for the endo-csophageal dilatation treatment of this condition, Walton believes that the most satisfactory and safest method of treating the advanced, difficult, and obstinate cases, in 


\section{Peroral Endoscopy}

which other methods have failed-as exemplified in his series-is by digital dilatation through the opened stomach, an operation first introduced, in $\mathbf{8 8 2 2}$, by Mickulicz. The author has successfully operated on 14 cases, but with one death in an emaciated male, aged 66, suffering in addition from advanced cardiac disease. The other patients were cured of all their symptoms. According to the author, the patients after operation are able to lead a normal life, eating and drinking anything. In one case twelve years had elapsed since the operation.

Whether the author's views prove to be correct remains to be confirmed by further research work. This is a highly thoughtful, comprehensive, and analytical review of the subject, which does great credit to the author, and is well illustrated by a number of X-ray pictures of the œsophagus in his cases before and after treatment.

IRWIN MOORE.

\section{A Neze Method for the Early Diagnosis of Mediastinitis after Wounds of the Esophagus from Foreign Bodies. W. Minnigerode. (Zeitschr.f. Hals-, Nasen-, Ohrenheilkunde, February r 923.)}

The problem of the diagnosis and treatment of purulent mediastinitis is a very important one, as the condition, if untreated, leads almost inevitably to a fatal termination. Damage to the walls of the œsophagus is not always avoidable when the foreign bodies are jagged, as repeated efforts at swallowing have a tendency to cause rapid perforation. Blunt objects causing slow erosion are not so dangerous, as there is time for an inflammatory zone to form around them and so limit the infection. The initial trauma is beyond our control, but damage due to blind attempts at removal is avoidable, and no effort to remove the foreign body should be made except under the guidance of the eye.

$\mathrm{X}$-ray photographs are of very great value in the majority of cases and should be employed before cesophagoscopy. Oblique projection so as to avoid the vertebral column is preferable.

If a lesion of the pharyngeal or œsophageal wall is already present, it is important to know at what level it is. The majority of foreign bodies lodge in the mouth of the cesophagus, and these are the most favourable for extraction. When they are situated in the thoracic œsophagus, removal by any method is much more difficult. In œsophagotomy the finger will normally reach downwards only to the level of the fifth or sixth thoracic vertebra, and from the stomach upwards to the seventh or eighth. Besides the position of the lesion, it is important to discover the degree of laceration. If the muscle is perforated, the prognosis must be very guarded.

Whenever there is a wound of the hypopharynx or gullet, the 


\section{Abstracts}

patient must be strictly confined to bed in hospital and the temperature accurately taken every three hours. There must be complete rest of the wounded organ, and it is imperative that absolutely nothing must be swallowed, not even saliva. Feeding must be done by the rectum or through a nasal feeding-tube passed well below the wounded area. The pelvis should be raised to prevent spread of infection downwards. Every act of swallowing tends to press some of the contents of the œsophagus through the wound into the surrounding tissue. During the passage of a bolus the pressure inside is fairly high, and air or liquid contents escape through the puncture. In the thorax there is even a suction from without as well as pulsion from within. The signs of inflammation following a perforated wound are not evident immediately, but escape of air into the tissues may occur at once where it can often be felt by the finger. This constitutes an urgent indication for immediate external operation. By using lateral photographs on small plates ro by $15 \mathrm{~cm}$. pressed tightly against the side of the neck, it is possible to detect very early inflammatory changes in the posterior pharyngeal wall. The normal thickness of this part is about $\mathbf{I} \mathrm{cm}$. A slight increase in thickness without other symptoms, such as fever, tenderness, or palpable swelling, does not of itself indicate operation, but it means a dangerous condition which needs careful observation. A considerable increase in thickness probably means abscess formation. A light streak on the negative in the posterior pharyngeal wall indicates the presence of air in the tissues and means commencing infection. Four cases are reported in detail in which the value of repeated X-ray plates was very clearly shown.

The paper is well illustrated with instructive photographs which show all degrees of infection.

J. K. Milne Dickie.

\section{Esophagotomy for Foreign Bodies in the Esophagus. PhILemon E. Truesdale, M.D. (Annals of Surgery, September 1924.)}

In this paper a case is made out for œsophagotomy as against endoscopic procedures in emergency cases in the country, where no expert is available who can confidently undertake the latter method.

Endoscopic procedures should only be undertaken by experts, as even moderately difficult cases demand " talent, ingenuity, adroitness, perhaps consummate skill acquired only after many years of convergent practice."

The author states that "deaths from the efforts to remove foreign bodies in the œsophagus through the mouth are more common than is generally supposed." He quotes Ingals as saying, "we have reason to believe that in general there may be a large percentage of mortalities." Jackson states that his mortality of 2 per cent. or less 


\section{Reviews of Books}

must be many times greater in the hands of those without adequate training and experience. The author doubts if the high mortality, 20 to 45 per cent. (referred to by Jackson), after œsophagotomy represents the results of this operation in the hands of experienced surgeons under favourable conditions. He puts it down to previous "over-treatment" with probing and cesophagoscope used as first aid. "In order that the operation may have the best chance of success when it is indicated, it is essential that no preliminary probing of any sort through the mouth be allowed."

Nicol M. Rankin.

\section{REVIEWS OF BOOKS}

The Medical Annual: A Year-Book of Treatment and Practitioner's Index for 1925 (Forty-third Year). Pp. 608. Bristol: John Wright \& Sons, Ltd.; London: Simpkin, Marshall, Hamilton, Kent \& Co., Ltd. Price 20 s. net.

The Medical Annual again more than justifies its existence. The way of the specialist is made easier by the admirable summaries of the papers published in the past year, and those in this issue are of at least as great interest and value as ever. Mr A. J. M. Wright is responsible for the sections on diseases of the Ear, Nose, and Throat, and has handled them with his usual conscientiousness and skill. Many important practical points are emphasised, such as Gray's insistence that progressive deafness in old people is often the result of Eustachian and middle-ear catarrh, and not due, as is too frequently assumed, to essential senile degeneration. Josephson's identification of a type of laryngitis affecting mainly the ventricles is another point. The csophagus is at present an organ of special interest in view of the progress made in radioscopic diagnosis and in treatment by mechanical and radiological methods. Vinson's advocacy of gradual mechanical dilatation as the result of his observations in the Mayo clinic is very striking. The surgery of the nasal accessory sinuses is always presenting something fresh. The through-andthrough drainage of the frontal sinus and the intranasal radical operation on the antrum receives due consideration.

The specialist will find much information of use to him in the sections devoted to general medicine and surgery and to specialties other than his own. Stridor in children interests laryngologists and pædiatrists alike, and Dr Langmead's section on this subject (p. 432) deserves careful perusal. Sir W. de Courcy Wheeler's ingenious 